\title{
The Effect of Using e-Tracking System for Small Enterprise
}

\author{
Kunyanuth Kularbphettong, Soraya Chalowattana, and Satien Janpla
}

\begin{abstract}
This paper present the results of using e-Tracking system based on web application for small enterprise to provide and manage documents and operations of the publisher. The proposed system can solve problems of processes and operations daily and it is easy to use and reduce data loss problems. Also, the application was designed to support and enhance document tracking system on Web site. At the evaluation stage, the developed system was evaluated the performance by experts and users. Questionnaires and Black Box Testing were used to measure the performance and satisfaction of the proposed application. The results were satisfactory as followed: Means for experts and users were 4.23 and 4.16 respectively.
\end{abstract}

Index Terms-Effect, e-tracking system, document tracking system, black box testing.

\section{INTRODUCTION}

"Technology will change the way your job" with the advent of information technology, adapting technologies can be possible to enhance and to automate much of the work currently carried out by humans [1]. The pace of technological change is rapidly moving for organizations because technology allow worker to communicate easily and improve and renovate the process of business.

Internet is one of the easily and fast efficient factors to promote community's products and it encourages the community to look forward to opportunity to share and promote knowledge. Recently, web technology has rapidly evolved and users can easily access web sites at any place and any time. Most organizations, both public and private sectors, have introduced more information technology related to electronic document management to optimize the agility, convenience and speed of document management, documents are mostly in the form of paper. A document management system is a computer system used to track, manage and store documents and reduce paper. Most are capable of keeping a record of the various versions created and modified by different users [2].

Therefore, the purpose of this research aims to develop e-Document Tracking system based on web application and it provides to keep copies of documents to digital and to track and view from the system anytime in order to resolve problems of operation working. The system enabled to manage electronic documents including creating, storing,

Manuscript received January 20, 2018; revised May 27, 2018. This work was supported by Suan Sunandha Rajabhat University.

The authors are with Computer Science Program, Faculty of Science and Technology, Suan Sunandha Rajabhat University, Thailand (e-mail: kunyanuth.ku@ssru.ac.th, Soraya.ch@ssru.ac.th, satien@ssru.ac.th). indexing monitoring and searching documents. Moreover, it is also beneficial to enhance communication efficiency in organizations. The remainder of this paper is organized as follows. Section II we describe research objectives and Section III presents methodology based on the purposed model. Section IV shows how to develop this application and the results is elaborated in Section V. Finally, the conclusion and future research are presented in Section VI.

\section{ReSEARCh OBJectives}

This research aimed to develop the e-Document Tracking application of the publishing company and to evaluate the user satisfaction of this system.

\section{ReSEARCh METHOdOlOGIES}

RAD (Rapid application development) was applied to design and implement this project. Unlike Waterfall methods, RAD is the most basic form minimizes planning and intensifies prototyping to quickly adjust to shifting requirements in a fast-paced [3]. According to James Martin approach [4], RAD divides the process into four distinct phases: Requirements planning phase; User design phase; Construction phase and Cutover phase. Fig. 1 was presented the processes of RAD approach [5].



Fig. 1. Rapid application development [5].

Black box testing is the method of software testing and it is used to test without looking at the internal structure of code or program [6], [7]. The steps of perform black box testing includes 1) examining specifications and requirements in the beginning stage 2) selecting valid inputs 3) determining expected outputs 4) constructing test cases 5) executing test cases 6) comparing actual outputs and 7) fixing and retesting [8].

\section{System DeVELOPMENT}

To development e-Document Tracking application, data was surveyed and collected from user's requirements so that the electronic document management system is similar to the 
old system and users can learn and understand the new system easily. In requirements planning phase, information was collected as a source of information for planning and analysis system and the related documents were divided into two parts: 1) internal documents and 2) external documents. The study can be divided the processes of operations into 4 sections: data storage, data processing, resource management and data monitoring. Each section encounters a problem like data storage problem, data fragmentation, data loss, and invalid data.

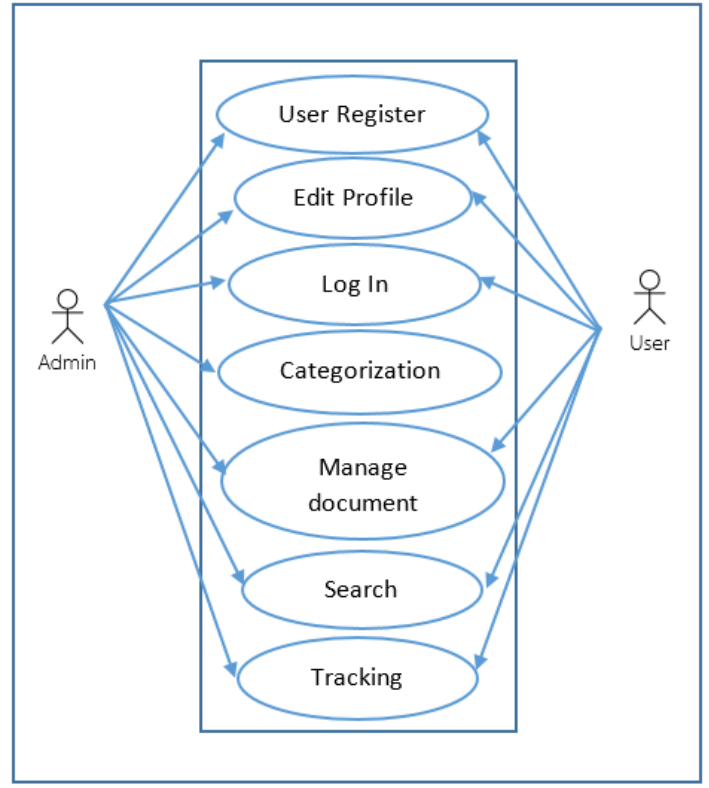

Fig. 2. Use case diagram of the system.

UML (Unified Modelling Language) was used in user design phase process and comprised the following diagrams:

1) Use Case Diagram acted to define the scope of the system.

2) Class Diagram acted to define the information of relational tables to show class, attribute, method and related relationships.

3) Activity Diagram acted to define the activities and working processes of the system. Submit your manuscript electronically for review.

Use Case diagram shows the work flow system from the user perceptions, as shown in figure 2 and figure 3 was presented the ER diagram of this project. The system manages the membership and authenticates access and can search documents both from the date of the document, and the number of documents.

When completed the analysis process, the next step was the graphics user interface (GUI) on this application. The main tool for developing the system is PHP and MySQL database management system was used to manage database. Black box Testing and Questionnaires with 3 experts and 30 users were applied to test and evaluation a web application system. Black box testing was tested based on the performances of the system and collected errors of the system. Questionnaires were tested for user's satisfaction. The questionnaires consisted of checklist and Likert scales. It comprised three main parts. The first part of questionnaires included the questions of demographic and the second part was evaluated the performance and satisfaction of the application and the last was tested the standard of black box testing. To evaluate the quality assessment system, Mean (x) and standard deviation (SD) were used to assess the qualities of the project.

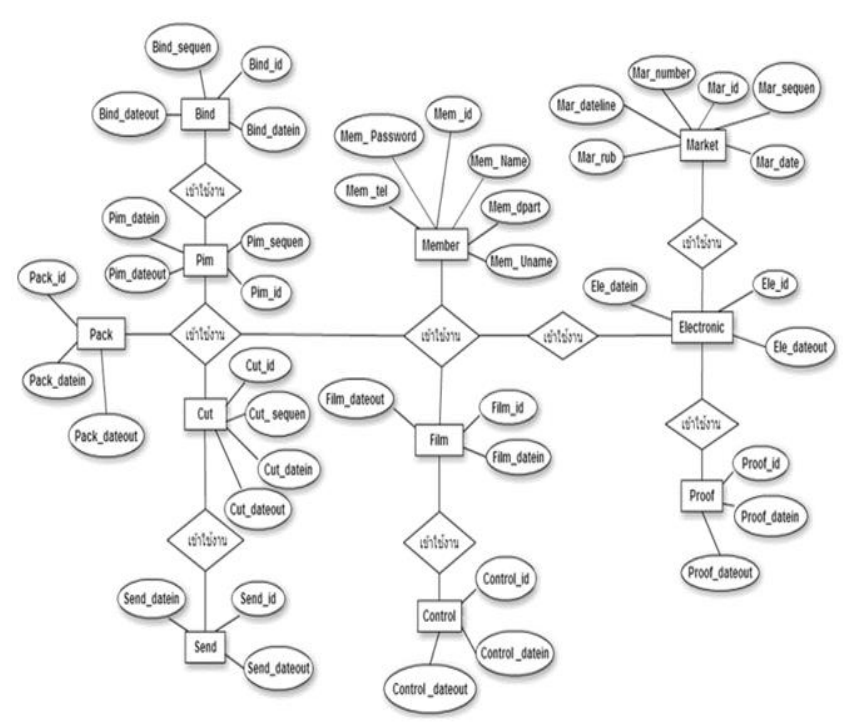

Fig. 3. ER diagram of the system.

\section{EXPERIMENTAL RESULTS}

In this section, experimental results were separated to 2 parts: developing the e-Tracking System based on Web Application and evaluating the performance and satisfaction of the application.

\section{A. Developing the e-Document Tracking System}

To develop the web application, Adobe Dreamweaver, PHP, HTML, CS6, AJAX and Java Script language were used to implement with MySQL database. Fig. 3 and 4 were shown the results of web application. The system consists of the subscriber system, search system, categorization system and map. The first page is displayed the menu keys such as search, menu and map and in the map search, if the user clicks on the map, the system displays a map from and shows the position of e-Tracking System. For a system administrator, the system is required to log in with username and password and the application will manage related information in database.

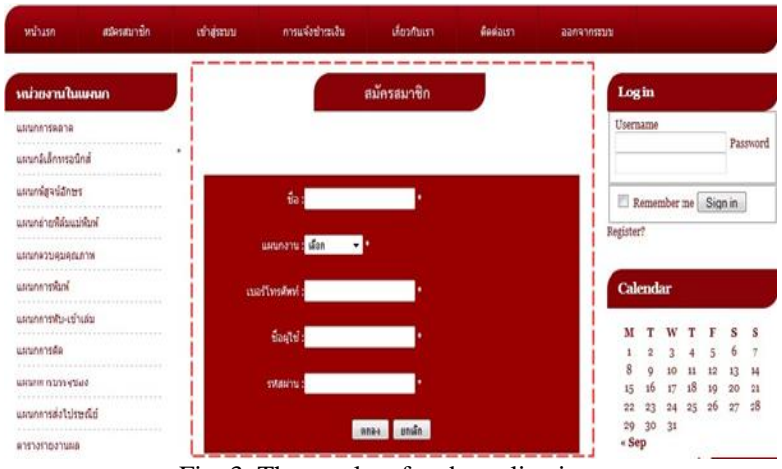

Fig. 3. The results of web application.

\section{B. Evaluating the Performance and Satisfaction of the Application}

When tested and evaluated the user's satisfaction and the qualities of the system, Black box Testing and 
Questionnaires by specialists and users were used to test this project [9], [10]. Black box testing acts as a "black-box" because it doesn't explicitly use Knowledge of the internal structure or code. Black Box testing was determined the error of the project as following: functional requirement test, Function test, Usability test, Performance test and Security test [11].

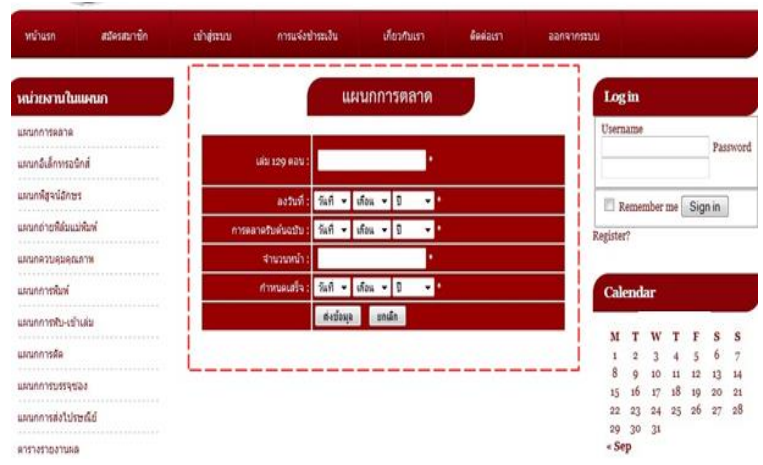

Fig. 4. The search page of the system.

TABLE I: THE RESULTS OF THE USER'S SATISFACTION SYSTEM

\begin{tabular}{|c|c|c|c|c|}
\hline & \multicolumn{2}{|c|}{ Experts } & \multicolumn{2}{|c|}{ Users } \\
\hline & $\overline{\boldsymbol{x}}$ & SD & $\overline{\boldsymbol{x}}$ & SD \\
\hline \multicolumn{5}{|l|}{ The ability of the system } \\
\hline $\begin{array}{l}\text { 1. the ability of the system to } \\
\text { provide information }\end{array}$ & 4.57 & 0.53 & 4.50 & 0.85 \\
\hline $\begin{array}{l}\text { 2. the ability of the system to link } \\
\text { menu }\end{array}$ & 4.71 & 0.49 & 4.60 & 0.70 \\
\hline 3. the ability of the system to search & 4.86 & 0.38 & 4.80 & 0.42 \\
\hline $\begin{array}{l}\text { 4. the ability of the system's } \\
\text { response time }\end{array}$ & 4.00 & 0.82 & 3.80 & 0.42 \\
\hline $\begin{array}{l}\text { 5. the ability of the system to work } \\
\text { automatically }\end{array}$ & 4.29 & 0.49 & 4.60 & 0.70 \\
\hline $\begin{array}{l}\text { 6. the ability of the system to } \\
\text { manage the database }\end{array}$ & 4.86 & 0.38 & 4.80 & 0.42 \\
\hline \multicolumn{5}{|l|}{ The accuracy of the system } \\
\hline $\begin{array}{l}\text { 1.the accuracy of the system to } \\
\text { display information }\end{array}$ & 4.86 & 0.48 & 4.57 & 0.79 \\
\hline $\begin{array}{l}\text { 2. the accuracy of the system to } \\
\text { information retrieval }\end{array}$ & 4.43 & 0.53 & 4.57 & 0.53 \\
\hline $\begin{array}{l}\text { 3. the accuracy of the system to } \\
\text { update }\end{array}$ & 4.43 & 0.53 & 4.70 & 0.48 \\
\hline $\begin{array}{l}\text { 4. the accuracy of the system in } \\
\text { storage }\end{array}$ & 4.57 & 0.79 & 4.86 & 0.38 \\
\hline $\begin{array}{l}\text { 5. the accuracy of the system to } \\
\text { report }\end{array}$ & 4.29 & 0.49 & 4.60 & 0.70 \\
\hline $\begin{array}{l}\text { 6. the accuracy of the system in the } \\
\text { overall system functions }\end{array}$ & 4.86 & 0.8 & 4.57 & 0.60 \\
\hline \multicolumn{5}{|l|}{ The suitability of the system } \\
\hline $\begin{array}{l}\text { 1.the suitability of the functions } \\
\text { with ease of system usage }\end{array}$ & 4.86 & 0.48 & 4.60 & 0.7 \\
\hline $\begin{array}{l}\text { 2. the suitability of text display } \\
\text { clarity }\end{array}$ & 3.86 & 0.53 & 4.7 & 0.67 \\
\hline 3. the suitability of using color & 4.00 & 0.58 & 4.7 & 0.67 \\
\hline 4. the suitability of data presentation & 3.71 & 0.49 & 4.5 & 0.53 \\
\hline 5. the suitability of user interface & 4.14 & 0.78 & 4.4 & 0.52 \\
\hline \multicolumn{5}{|l|}{ The speed of the system } \\
\hline a whole & 4.29 & 0.49 & 4.50 & 0.71 \\
\hline 2. the sp & 4.43 & 0.53 & 4.40 & 0.70 \\
\hline 3. the $s$ & 4.29 & 0.49 & 4.60 & 0.70 \\
\hline g the link & 4.00 & 0.82 & 4.30 & 0.67 \\
\hline 5. the speed of editing data & 3.86 & 0.69 & 4.60 & 0.52 \\
\hline \multicolumn{5}{|c|}{ The security and verify data of the system } \\
\hline $\begin{array}{l}\text { 1. the security and verify data of set } \\
\text { the permissions of using }\end{array}$ & 4.43 & 0.53 & 4.70 & 0.48 \\
\hline $\begin{array}{l}\text { 2. the security and verify data of } \\
\text { determining a user account }\end{array}$ & 4.71 & 0.49 & 4.70 & 0.67 \\
\hline $\begin{array}{l}\text { 3. the security and verify data of } \\
\text { verify the accuracy of input data }\end{array}$ & 4.29 & 0.76 & 4.30 & 0.67 \\
\hline
\end{tabular}

Functional Requirement test was evaluated the ability of the system to serve the needs of the users and Functional test was used to evaluate the accuracy of the system. Usability test was tested the suitability of the system. Performance test was assessed the processing speed of the system. Finally, Security test was used to evaluate the security of the system Table I was shown the results of user's satisfaction.

The table shows that assessment of the ability of the system to meet the needs of the experts and users respectively in average of 4.55 and 4.52 and standard deviation of 0.54 and 0.59 so that satisfaction in quality toward the system is well.

\begin{tabular}{|l|l|l|l|l|}
\hline \multirow{2}{*}{ TABLE II: THE RESULTS OF THE BLACK BOX TESTING OF THE SYSTEM } \\
\cline { 2 - 6 } & $\overline{\boldsymbol{x}}$ & SD & $\overline{\boldsymbol{X}}$ & SD \\
\hline 1.Function Requirement Test & 4.55 & 0.54 & 4.52 & 0.59 \\
\hline 2. Functional Test & 4.60 & 0.58 & 4.50 & 0.60 \\
\hline 3. Usability Test & 4.11 & 0.44 & 4.70 & 0.48 \\
\hline 4. Performance Test & 4.17 & 0.60 & 4.48 & 0.66 \\
\hline 5. Security Test & 4.19 & 0.59 & 4.47 & 0.72 \\
\hline
\end{tabular}

The results show that a quality assessment of the system is well in all aspects and Mean were 4.32 and 4.53 and standard deviation were 0.55 and 0.61 . It can be concluded that the traditional occupation web base application is good.

\section{CONCLUSION}

In this work, we developed e-Tracking application based on web Application. This system provides more suitable to keep track of the publisher in order to resolve problems of working with in a day. Also, expert and user are satisfied the system performance. From the results of this application, this study presents the system can meet the needs of users and this system can be beneficial to manage documents. However, this application needs to be analyzed to meet the needs of the new system and adapted to be suitable for requirements of other requirements.

\section{ACKNOWLEDGMENT}

This study was successful by financial support from Suan Sunandha Rajabhat University and many helps from my colleagues.

\section{REFERENCES}

[1] Derek O'Halloran. Emerging Technologies. [Online]. Available: https://www.weforum.org/agenda/2015/08/how-technology-will-chan ge-the-way-we-work/

[2] Document management system. [Online]. Available: https://en.wikipedia.org/wiki/Document_management_system

[3] S. Stiner. Rapid Application Development (RAD): A Smart, Quick and Valuable Process For Software Developers. [Online]. Available: https://www.forbes.com/sites/forbestechcouncil/2016/08/24/rapid-app lication-development-rad-a-smart-quick-and-valuable-process-for-soft ware-developers/\#715a9f2019e8

[4] Javatechig. Rapid application development model. [Online]. Available: http://javatechig.com/se-concepts/rapid-application-development-mod el

[5] A. Ghahrai. Rapid application development (RAD). [Online] Available:

https://www.testingexcellence.com/rapid-application-development-ra d/

[6] M. G. Limaye, "Software testing," Tata McGraw-Hill Education, p. 216, 2009. 
[7] Black-box

testing.

[Online]. https://en.wikipedia.org/wiki/Black-box_testing

[8] Black Box Testing: Types and Techniques, The Official 360logica Blog. [Online].

Available: https://www.360logica.com/blog/black-box-testing-types-techniques/

[9] L. Williams, "Testing overview and black-box testing techniques," 2006.

[10] N. Tachapetpatboon and K. Kularbphettong, "Ontology based knowledge management for cultural tourism," Journal of Theoretical \& Applied Information Technology, vol. 75, iss. 3, pp. 384-388.

[11] L. Copeland, A Practitioner's Guide to Software Test Design, Boston: Artech House Publishers, 2004.

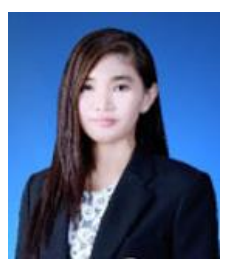

Kunyanuth Kularbphettong is with computer science program, Faculty of Science and Technology, Suan Sunandha Rajabhat University, Thailand.

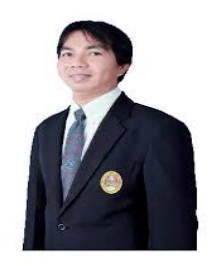

Satien Janpla is with computer science program, Faculty of Science and Technology, Suan Sunandha Rajabhat University, Thailand.

Soraya Chalowattana is with computer science program, Faculty of Science and Technology, Suan Sunandha Rajabhat University, Thailand. 